\title{
Analysis of the Energy Transmission System Performance after the use of Linear Reactor and Saturated Reactors for Voltage Regulation.
}

\author{
A. B. Vasconcellos ${ }^{1}$, Dr.; T.I.R.C. Malheiro ${ }^{2}, \mathrm{PhD}$; \\ I.M. Faria ${ }^{1}$, Eng.; G.N. Lopes ${ }^{1}$,Std.; V.H.F. Brito ${ }^{1}$, Eng. \\ ${ }^{1}$ Federal University of Mato Grosso (UFMT), Electrical Engineering Department - Cuiabá (Brazil) \\ ${ }^{2}$ Federal Institution of Education, Science and Technology of Mato Grosso - IFMT - Cuiabá (Brazil) \\ e-mail: arnulfo@ufmt.br, malheiro.teresa@gmail.com, iago_mf@hotmail.com, ggagabiene@outlook.com, \\ viniciushfb2@gmail.com.
}

\begin{abstract}
This paper presents theoretical considerations, performance studies of linear and saturated reactors for voltage control purposes in transmission systems. The simulations will be made through ATPDraw simulator, which uses representation techniques in the time domain, such devices are modelled. By selecting a case study, issues associated with voltage regulation process are investigated, highlighting the specific features in each solution, when some variation is imposed to the network loading. Through this case study, the article highlights the advantages and disadvantages linked to each of these devices.
\end{abstract}

\section{Key words}

Linear Reactor, Saturated Reactors, Modeling, Tension Control and Transmission Gain.

\section{Introduction}

The Brazilian electrical system, due to the long territorial extensions, is in a country where the use of transmission lines over long distances is a fairly common practice. This is mostly due to the fact that energy consumption is concentrated in specific regions and energy generation is predominantly hydraulic, in very distant areas. One of the main features of high voltage long transmission systems, is the difficulty associated with the control and adjustment of the voltage in consumer bars, both steady state and transient. Operating with no load or light loading, during the energization or due to load rejections, the capacitances associated with these lines often impose unacceptable increases in the voltage of consumption bars. On the other hand, when working in full load state, a reverse behaviour is registered, that is, the dramatic voltage reduction. Given this situation, many times, these voltage fluctuations in load bars exceed default values defined by regulators (ONS and ANEEL). This adverse situation is even more serious when the short circuit level of power system is lower. To resolve the issue, the solution, in most cases, relies on devices based on reactive compensation. In fact, this is a common practice among the concessionaires responsible for the generation and transmission of electricity, each company using different methods, with specific characteristics and indications.
Among these features stand out, among the more traditional and less expensive, the linear reactors and capacitors, with fixed values and connected in shunt. In this structure, the reactors prevent the voltage from reaching high levels, while the capacitors act in the opposite direction, preventing low levels, below the acceptable range.

The disadvantages observed with the use of this compensation scheme consist primarily in the need of executing equipment insertion or removal manoeuvres whenever the system load experiences significant changes. Thus, when the load supplied by the line is reduced, the capacitors must be gradually withdrawn from operation to restrain the growth of the voltage, while the reactors will be engaged in a identical manoeuvre when consumption increases. The voltage regulation achieved by such procedures does not exhibit, therefore, a continuous profile, but discrete, since only blocks of these elements may be activated at a time. Moreover, the voltage containment in the context of a load rejection requires the permanence of linear reactors in continuous operation, indifferent to the loading imposed to the transmission line and under these circumstances, such equipment will exercise the role of a power reactive permanent consumer. Thus, the benefits earned from the operation of the linear reactors during low load regime will be fully countered in the full load operation, as part of the line transmission capacity will be occupied with their supply. This adverse situation is even more serious when taking into account the current efforts of companies in the electricity sector to raise the natural power of its transmission lines as the desired gains with this transaction will be partially frustrated by the presence of linear compensation reactors.

Given this situation, one of the alternatives to overcome the drawbacks of the conventional association reactor capacitor with fixed values and manoeuvrable via switching consists of the replacement of this set by rotary or static compensators. Without going into the details of these product lines, it is worth to note that any of these options, however, implies a sizable expenditure, not only to purchase and install properly the equipment, but also in infrastructure for their future maintenance and operation. Another equally effective proposition, but much less expensive, uses saturated reactors. 
In fact, the characteristic $\mathrm{V} \times \mathrm{I}$ of these devices, seems tailormade for the intended application as: at lower voltages, that is, the full-load condition, the reactor will operate in the linear region, demanding, thus a minimum reactive power of the system. As the system load gradually decreases, the voltage increases, moving the reactor operating point to the saturation region, increasing its consumption at a proportion determined by the slope of its characteristic which, in principle, can be specified to meet any level of desired compensation. Such behavior as well as allowing for a continuous control voltage within certain levels, will provide more capacity for the transmission line to meet the load. Besides these features, as its operating principle is similar to the power transformer in terms of construction technology, the saturated core reactor has the peculiarities of this kind of equipment.

Within the context above, the objective of this paper is to focus on the use of saturated core reactive compensation in terms of their comparative performance with traditional reactive compensation, that is, the one that uses linear reactors.

The static compensator with saturated core reactor is based on a combination of a magnetic core with special features and windings. This constructive property provides a robust equipment with low maintenance, good efficiency in voltage regulation and short response time. These elements contribute, undoubtedly, to make the use of saturated core reactors for compensation of transmission lines even more attractive.

Focusing in the replacement of Linear Reactors for Saturated Reactors to carry more active power in transmission lines, this paper aims to present results of performance studies, by ATPDraw modeling, of these devices and assess their impact in a typical transmission system of the brazilian electric grid.

For that Transmission Line of Eletronorte between the cities of Cuiabá and Sinop, in Mato Grosso State in Brazil, used. Investigations are intended to evaluate the effectiveness of saturated core compensator in voltage regulation and power gain . Different cases, comprising voltages elevations, under ideal conditions, are considered in the simulations.

The basic principles and operating characteristics of the static compensator with saturated core reactor, as well as their physical and corresponding computational model implementation are themes explored in [1-5], which is why such breakdowns are not included in this paper.

\section{System Characterization and Computational Studies}

The single-line diagram of the system used for the purpose of this paper is shown in Fig. 1, while some relevant information are found in Table I.

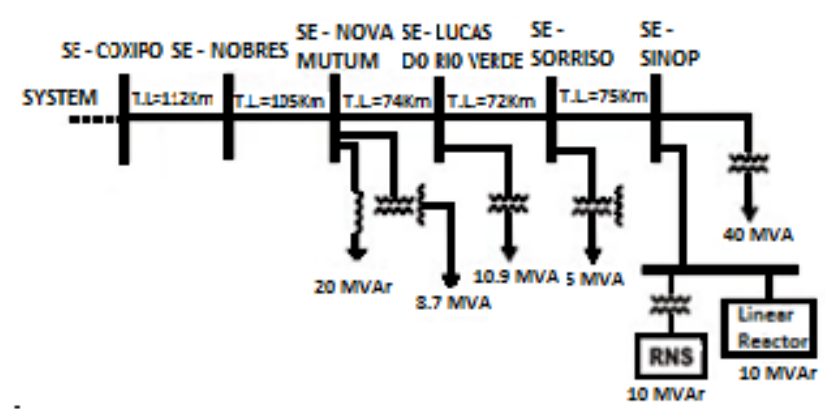

Fig. 1. Electrical system used in the simulation.

Table I - System Data.

\begin{tabular}{c|c|c|c|c|c} 
Data & $\begin{array}{c}\text { Power } \\
(\mathrm{MVA})\end{array}$ & $\begin{array}{c}\text { Power } \\
\text { Factor }\end{array}$ & $\begin{array}{c}\text { Voltage } \\
(\mathrm{kV})\end{array}$ & $\begin{array}{c}\text { Reactive } \\
\text { Power } \\
(\mathrm{MVAr})\end{array}$ & $\begin{array}{c}\text { Length } \\
(\mathrm{km})\end{array}$ \\
\hline Load & 40 & 0,92 & 138 & - & - \\
\hline Line Length & - & - & - & - & 438 \\
\hline Linear Reactor & - & - & 230 & 10 & - \\
\hline $\begin{array}{c}\text { Saturated } \\
\text { Reactor } \\
\text { (Twin-Tripler) }\end{array}$ & - & - & 13,8 & 10 & -
\end{tabular}

Based on the arrangement above characterized, some operative situations are considered, following, for the purpose of answering the questions on the central theme of this paper.

A. Analysis of a $230 \mathrm{kV}$ Sinop's substation bus - without the presence of linear and saturated reactors.

This situation aims, among other things, highlight the impacts linked with sudden loading relief of the main consumption point of the electric complex with operating voltages. Therefore, the analysis focuses, in particular, the effects on $230 \mathrm{kV}$ bus feeding the city of Sinop. In order to obtain levels that serve as references for comparison purposes, the results in question, although consider a complete network and two different conditions for the final load, do not contemplate the presence of the linear reactor or saturated core reactor, each one with rated power specified as 10 MVAr.

As can be seen in the oscillogram below, in $t=1 \mathrm{~s}$ an event assigned to a sudden loss of $75 \%$ of the present load on the secondary of the Sinop's transformer occurs. This effect, as seen, is responsible for an increase of $8.21 \%$ in tension, which lasts for $1 \mathrm{~s}$. After this interval the load is restored to its original value and voltage. The profiles of the voltages between phases in $230 \mathrm{kV}$ bus (1 p.u.) Sinop throughout the simulation interval (between 0.0 and 3,0s) associated with the operation defined above are indicated in Fig. 2. 


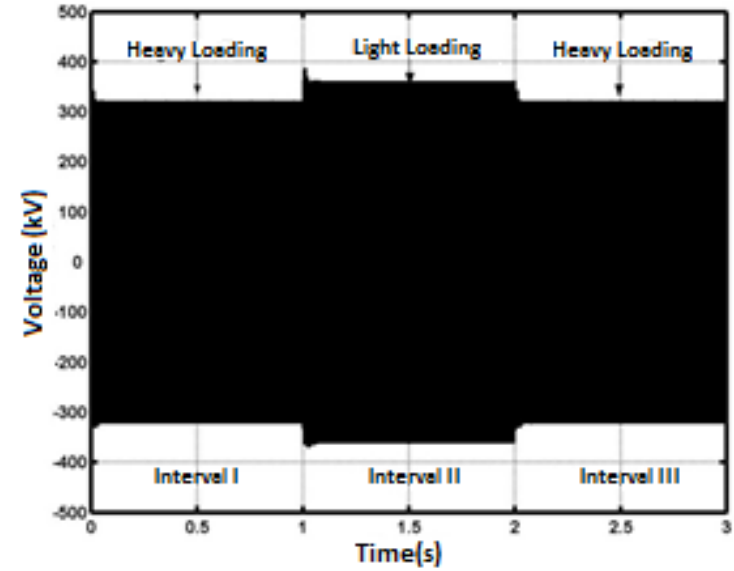

Fig. 2. Voltages between phases on the $230 \mathrm{kV}$ bus of Sinop- sudden relief $75 \%$ load - without linear reactor and saturated reactor.

In order to provide more information about the event that occurred, the Fig. 3 (a) and (b) illustrate, respectively, details of the voltage in Sinop for the two operating conditions of the system, one of them associated with what is called a normal load and another situation under the action of the sudden relief of the load. The results reflect the performance of the voltage without the presence if reactors and, before this situation, it can be seen that there was an increased voltage on the bus outside the standards allowed by regulators. The initial value, around $228,5 \mathrm{kV}(0.99 \mathrm{pu})$ in the range of 0.0 to $1,0 \mathrm{~s}$, was raised to $248,9 \mathrm{kV}(1.08 \mathrm{pu})$ in the range from 1.0 to $2,0 \mathrm{~s}$. This voltage resumes its initial value after the load restart, which occurs at $\mathrm{t} \geq 2,0 \mathrm{~s}$, as shown in Fig.2.

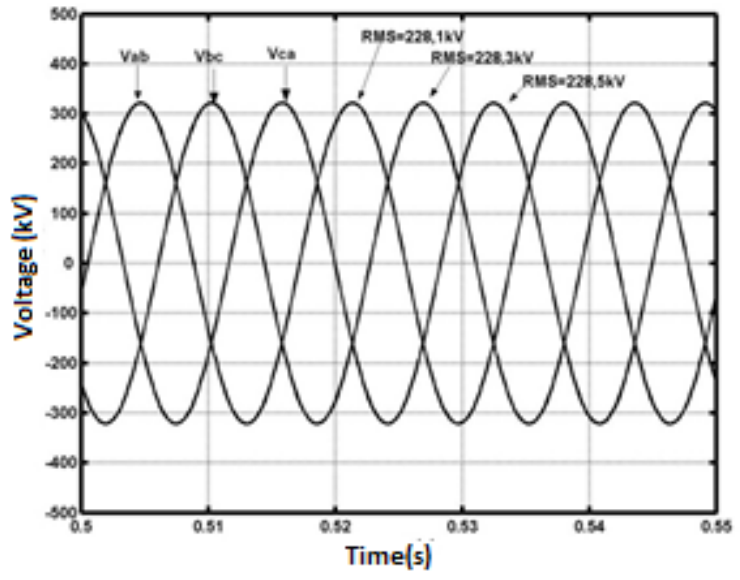

(a) Interval I

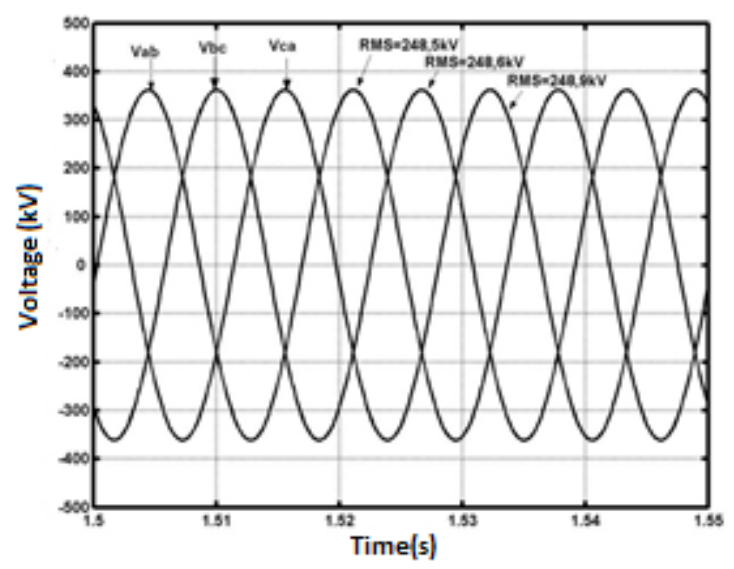

(b) Interval II

Fig. 3. Voltages between phases on the $230 \mathrm{kV}$ bus of Sinop- details for the conditions: (a) full load and (b) $75 \%$ relief of the load - without the presence of reactors: linear and saturated.

$+$

B. Analysis of Sinop's $230 \mathrm{kV}$ substation bus - with the presence of linear reactor.

This assessment expresses the same conditions, except that now, the electric complex will operate with the insertion of the 10 MVAr linear reactor, which was energized and is in continuous operation and in permanent regime. Thus, at $\mathrm{t}=$ $1 \mathrm{~s}$ the disturbance in focus is caused, that is, the removal of $75 \%$ of this load on Sinop's secondary transformer. The voltage between phases for the $230 \mathrm{kV}$ bus (1 p.u.) of Sinop throughout the simulation interval (between 0.0 and 3,0s) are indicated in Fig. 4.

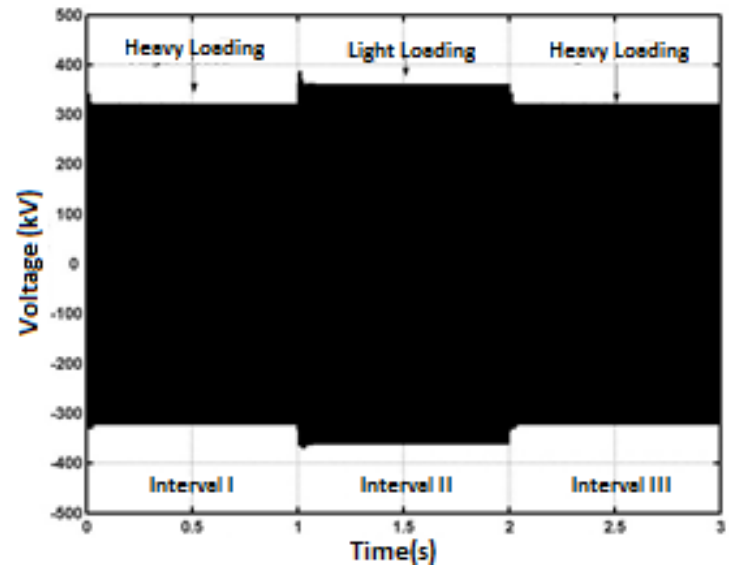

Fig. 4. Voltages between phases on the $230 \mathrm{kV}$ bus of Sinop- sudden relief $75 \%$ load - with linear reactor.

Fig. 5 (a) and (b) provide, respectively, details of Sinop voltages for original conditions and under the action of the sudden relief of the load. As it turns out, there was a voltage stabilization on the bus within the official standards due to the presence of compensation made by the linear reactor. The initial value of around $220,4 \mathrm{kV}(0.95 \mathrm{pu})$ in the range of 0.0 to $1,0 \mathrm{~s}$, was raised to $239,0 \mathrm{kV}(1.04 \mathrm{pu})$ in the range from 1.0 to $2,0 \mathrm{~s}$. This voltage resumes its initial value after the load restart, which occurs at $\mathrm{t} \geq 2,0 \mathrm{~s}$. 


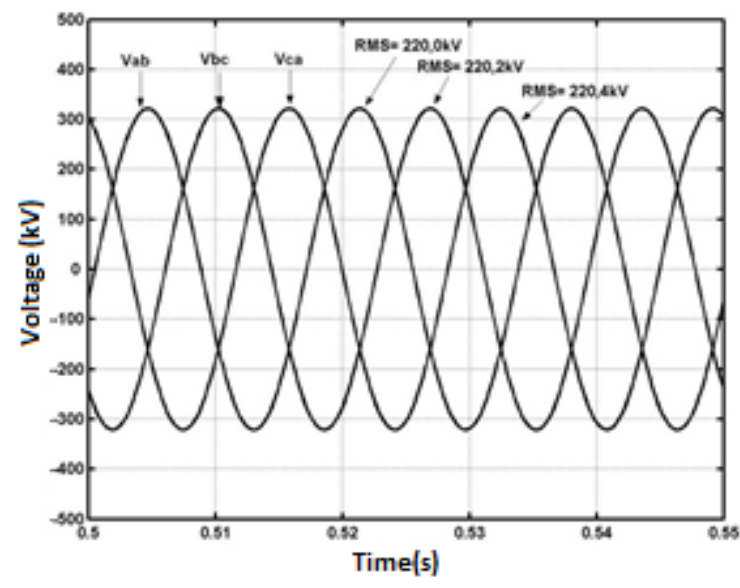

(a) Interval I

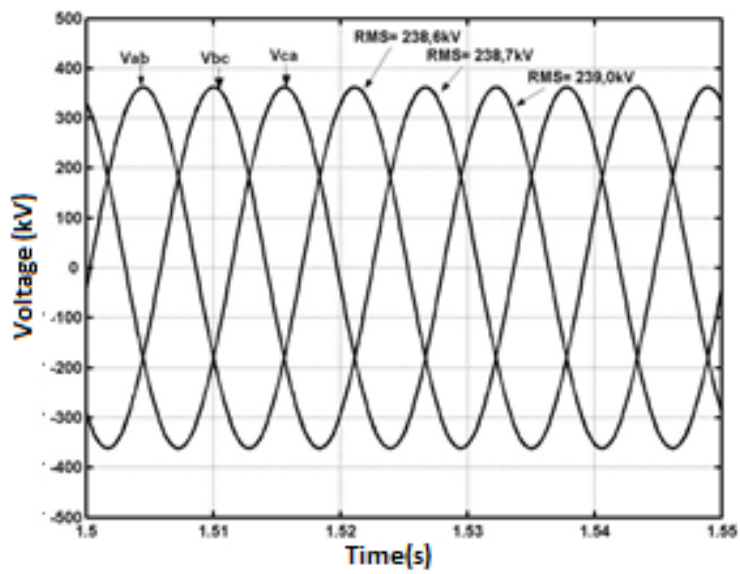

(b)Interval II

Fig. 5. Voltages between phases on the $230 \mathrm{kV}$ bus of Sinopdetails for the conditions: (a) full load and (b) $75 \%$ relief of the load - with linear reactor.

In order to clarify the operation of the linear reactor, Fig. 6 shows the current absorbed by the compensator device along the whole simulation range (between 0.0 and 3,0s).

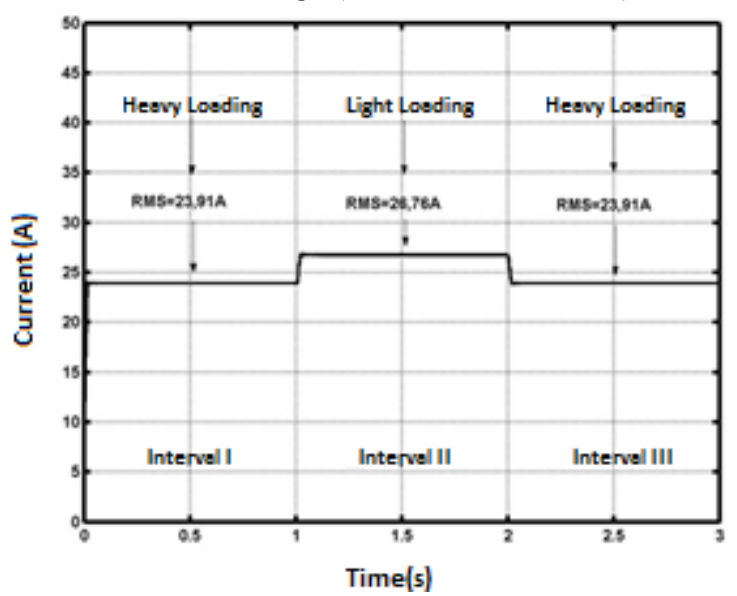

Fig. 6. Operating currentof the linear reactor - (Intervals I and III) with a heavy loading and (Interval II) with light loading.

The result above shows that the operating current, initially was $23,91 \mathrm{~A}$ under heavy load, is raised to $26,76 \mathrm{~A}$ during the momentary removal of $75 \%$ of the load. This equates to an increase of $11.91 \%$ of the operating current and its impact on the voltage regulation. This current, as expected, returns to its original value when load is restored to its initial value.
In addition, Fig. 7 indicates reactive power absorbed by the linear reactor during the simulation interval $(0.0$ to $3,0 \mathrm{~s})$. It shows that initial power of 9.08 MVAr was raised to 11.36 MVAr during the momentary removal of $75 \%$ of the load. These values indicate an increase of $25.11 \%$ of the reactive power absorbed during load relief. At the end, after the resumption of the normal load, the reactive power returns to its initial value.

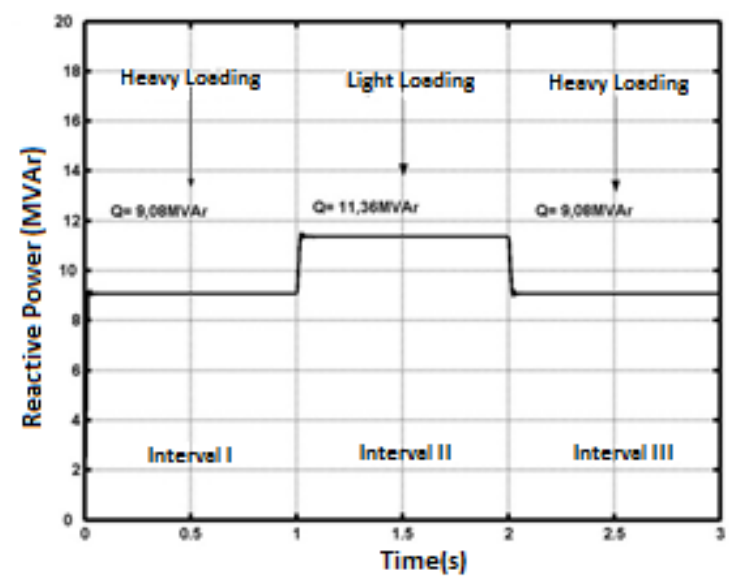

Fig. 7. Reactive Power in linear reactor -. (Intervals I and III) with a heavy load and (Interval II) with light loading.

C. Analysis of a $230 \mathrm{kV}$ Sinop's substation bus - with the presence of saturated reactor.

In the same ways as was done in the previous section, the voltage behavior at $230 \mathrm{kV}$ bus under the action of a 10 MVAr saturated reactor (saturated reactor core), was also evaluated. The physical location of the reactor can be seen in Fig. 1, showing the insertion $230 \mathrm{kV}$ bus via a step-down transformer $230 / 13.8 \mathrm{kV}$. The operating conditions are the same as already discussed, therefore there is no need for further information on the simulated event.

The Fig. 8 highlights the voltages to Sinop's $230 \mathrm{kV}$ bus ( 1 p.u.) throughout the study interval between 0,0 and 3,0s.

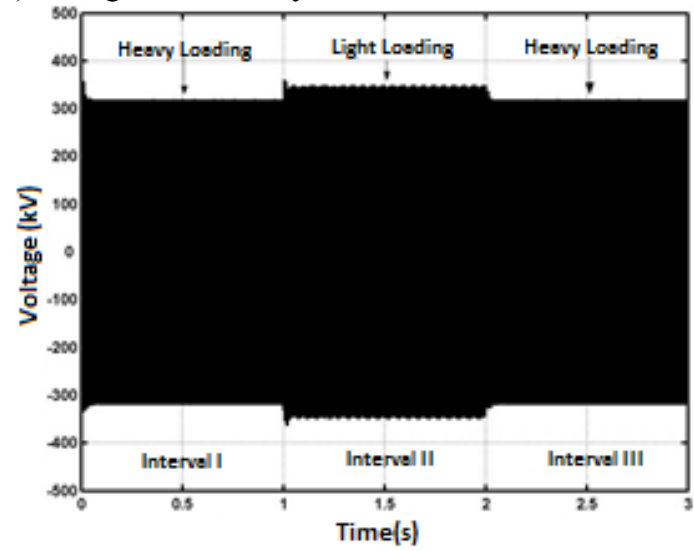

Fig. 8. Voltages between phases on the $230 \mathrm{kV}$ bus of Sinop- sudden relief $75 \%$ load - with saturated reactor.

Based on Fig. 9 (a) and (b), which detail the regions of interest for studies, the effectiveness of the saturated reactor for voltage regulation in Sinop can be verified. This which was initially $226.7 \mathrm{kV}$ (0.98 p.u.) was increased to $240.7 \mathrm{kV}$ (1,04p.u.) during the temporary removal of $75 \%$ of the load. As for the other studies, this voltage resumes its original value after the restoration of normal load. Accordingly, it has been verified that the reactor, acting to absorb reactive 
system, gave the desired compensation for the final operating voltage. Also, it is important to note that the initial voltage also presents better levels than those associated with the presence of linear reactor, and this was attributed to their intrinsic properties of operation, as noted earlier.

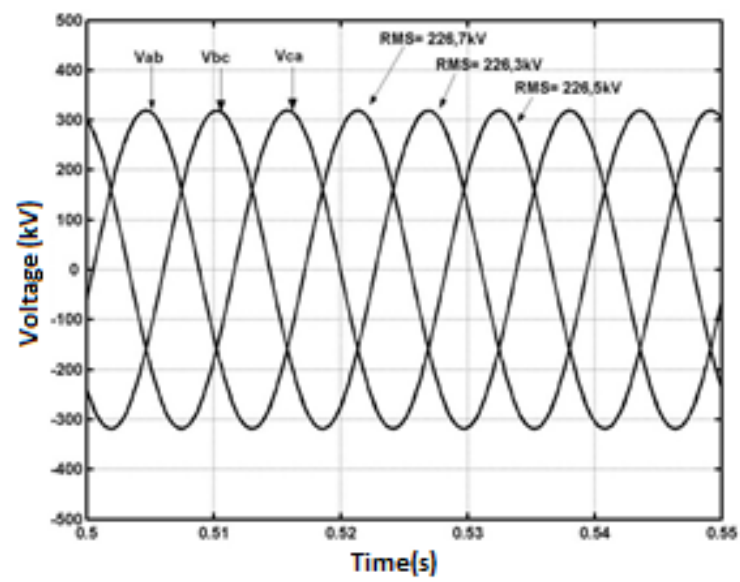

(a) Interval I

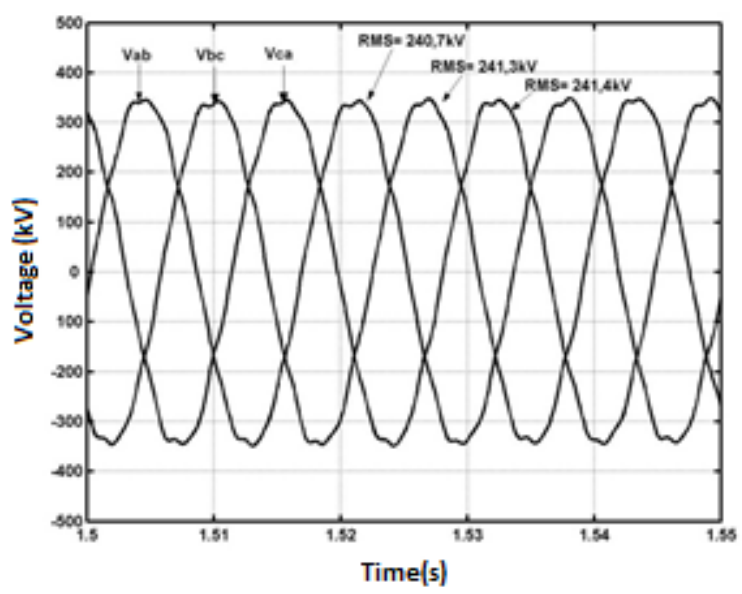

(b)Interval II

Fig. 9. Voltages between phases on the $230 \mathrm{kV}$ bus of Sinop- details for the conditions: (a) full load and (b) $75 \%$ relief of the load - with the presence of saturated reactor.

An important point to highlight during the performance of the saturated reactor refers to the issue of harmonic distortion detected. In fact, when looking at the results of Fig. 9 (b) the presence of harmonic distortions, which were not present in previous studies, are obvious. This finding, however, would be expected when considering the operating principle of the compensation equipment used. This, as established by the classical theory, produces harmonic currents when its operation, whose orders are similar to a rectifier system of 12 pulses. Therefore, the frequencies expected to be the most significant are orders 11 and 13, which is in line with the expected performance of a three-phase reactor of the TwinTripler type, which ideally generates harmonics of a $(12 \mathrm{~K} \pm$ 1) order [4],where $K$ is any positive integer number. Despite this disadvantageous aspect, the frequency spectrum shown in Fig. 10 reveals that the negative impacts did not produce distortion greater than reference levels recommended by the Brazilians laws that regulate it.

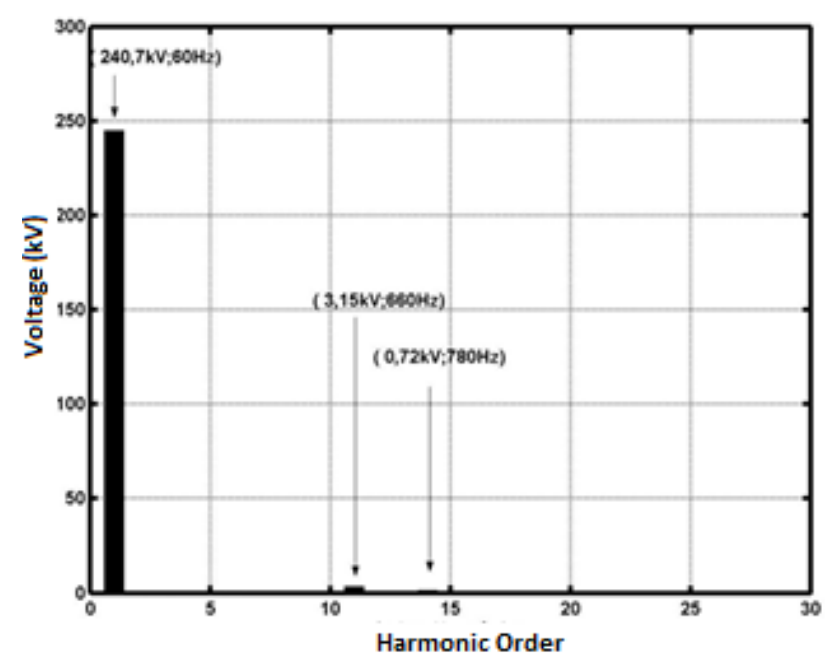

Fig. 10. Harmonic spectrum of $230 \mathrm{kV}$ bus voltage in Sinop during performance of RNS in charge of relief.

Regarding the current absorbed by the saturated reactor in the process under study, Figure 11 shows the performance and highlights, clearly, a very attractive property for the use of this equipment. It can be seen that the current absorbed by the saturated reactor core under heavy load, which was 5.46 $\mathrm{A}$, was increased to $27,82 \mathrm{~A}$, during the momentary removal of $75 \%$ of the load. This, differently from the linear reactor resulted in increase of $509.5 \%$ of the initial device operating current. This current resumes its original value when the load returns to normal.

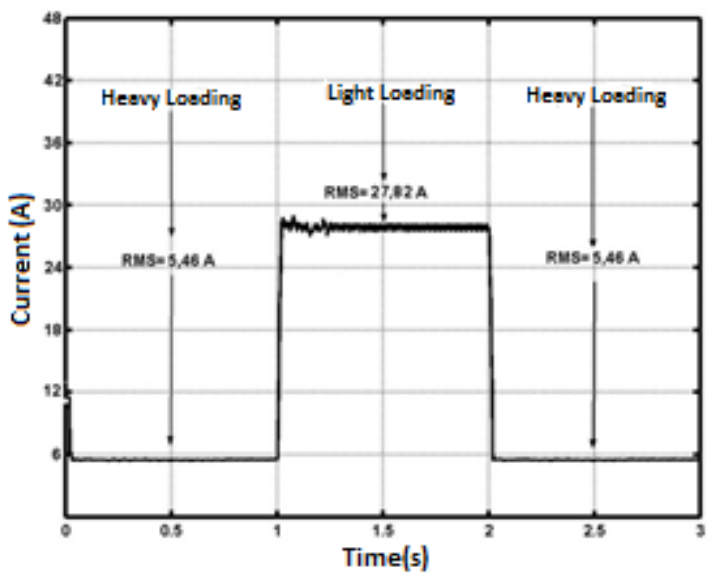

Fig. 11. RNS operating current - details for the conditions:. (Intervals I and III) with a heavy loading and (Interval II) with light loading.

Similarly, Figure 12 shows, for each operational situation, the reactive power absorbed by the saturated reactor. The figure makes it clear that the initial value of this magnitude was 4.10 MVAr during load shedding passes to 9.36 MVAr, thus corresponding to an increase of $2,28 \%$ of the original power. 


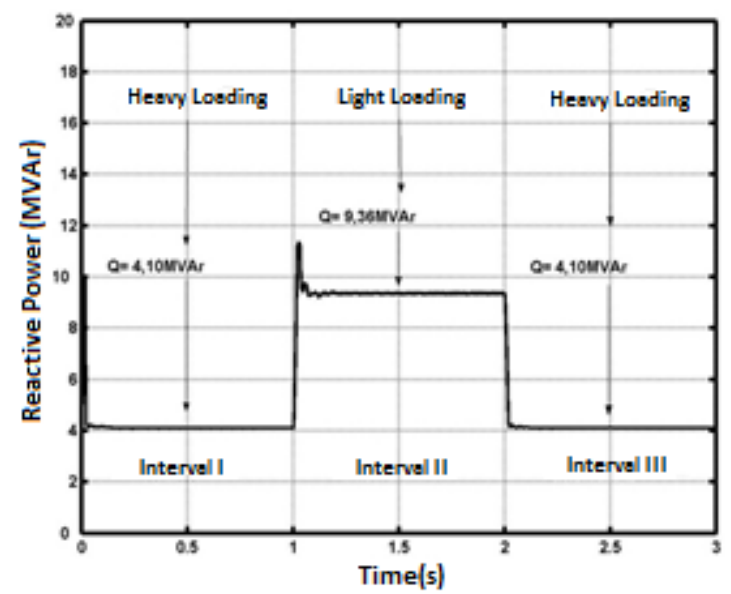

Fig. 12. Reactive Power in RNS - details for the conditions:. (Intervals I and III) with a heavy loading and (Interval II) with light loading.

\section{Synthesis of the results.}

In order to provide means for a direct comparison of the above results, Figure 13 shows, for all computational study period performed, the reactive power absorbed by the two types of reactors. The figure shows that under normal loading, the linear reactor absorbs reactive power $221.4 \%$ higher than the corresponding unsaturated device. Also, in the operating condition with the removal of $75 \%$ of the original charge, it has been demonstrated that the reactive power required by saturated is $21.36 \%$ lower than that required by the linear one[6].

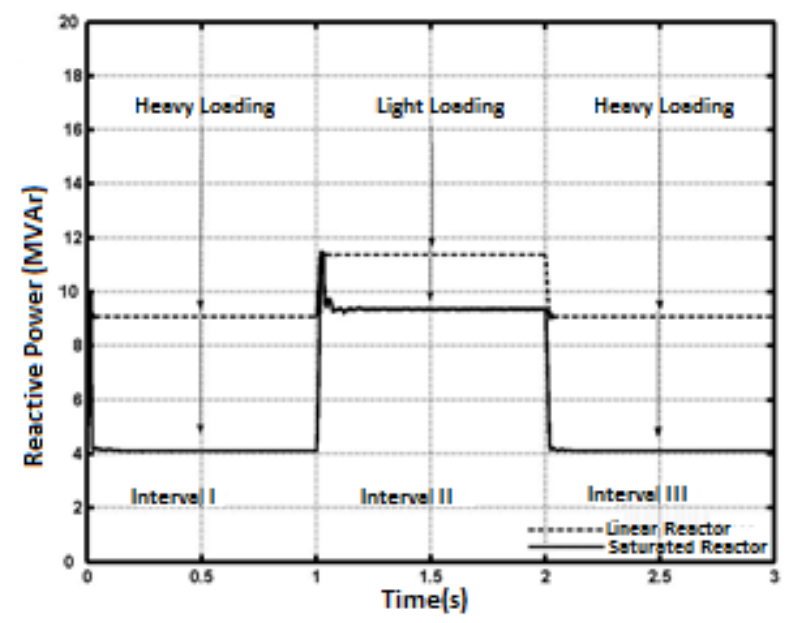

Fig. 13. Reactive Power in linear reactor and saturated core reactor - details for the conditions:. (Intervals I and III) with a heavy loading and (Interval II) with light loading.

Gathering other informations in the same image, Figure 14 provides a ready confrontation between the most representative quantities of the process as a whole. In Figure 14 shows grouped the results associated with: the values of the voltages under full and reduced loading, the current absorbed by the reactor and, again, the reactive power for the investigated situations. The operating conditions of the network in the absence of the reactors and with them are clearly indicated.

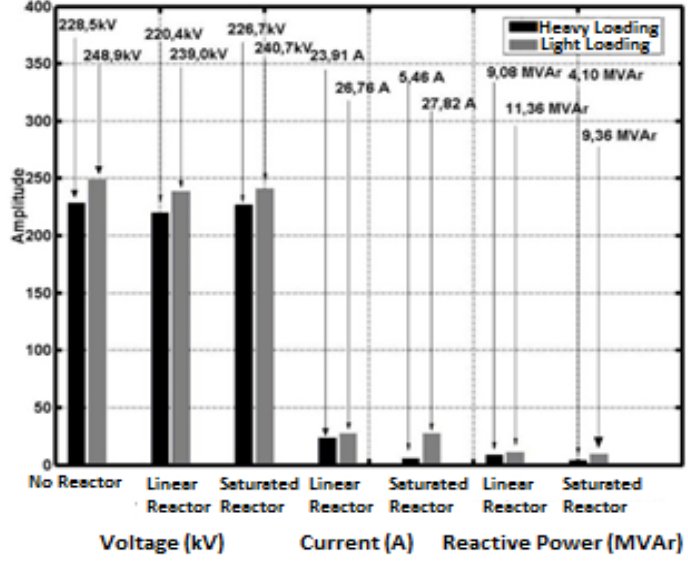

Fig. 14. Comparison Chart between the values of voltages, currents and reactive power - $230 \mathrm{kV}$ bus in Sinop

\section{Conclusion}

This article had the main focus to present the gains made when replacing linear reactors for corresponding devices using the intrinsic property of magnetic materials, that is, saturation. The central theme explored was directed to the use of such devices for voltage regulation in transmission lines without the worry of describing the models and their computational implementation. Aiming to clarify the advantages and disadvantages associated with each technology, using a real electric complex at $230 \mathrm{kV}$, system performance studies were performed on the occurrence of a phenomenon associated with the withdrawn rise of a significant portion of the load in a end of the line bus. The values obtained for the power required during operation of the reactors showed significant advantage when employing the saturated units, which, as highlighted in this paper, besides providing a better margin for voltage regulation, also led to a relief in the transmission network. As a negative point when installing the saturated reactors, the article showed that such a device, due to its non-linear characteristic, constitutes a source of harmonic currents injected into the grid. Notwithstanding this fact, for the focused case, such problems did not occur in worrying proportions, a conclusion that cannot be readily extended to other applications.

\section{References}

[1] Oliveira, J. C., Vasconcellos, A. B., Apolônio, R. - "Compensador Estático a Reator Saturado: Geração Harmônica Sob Condições Ideais e Não Ideais de Suprimento.” V SBQEE, Aracaju - Sergipe - Brazil, 17 a 20th August 2003

[2] J. C. Oliveira, A. B. Vasconcellos, R. Apolônio; "Análise do Desempenho Dinâmico de um Compensador Estático a Reator a Núcleo Saturado"; VI SBQEE, Aracaju-SE, Brasil, August/2005.

[3] J. C. Oliveira, A. B. Vasconcellos, R. Apolônio; "Saturated Core Reactor Static Compensator: Computational Analysis Versus Experimental" (in Portuguese), XV CBA, Gramado-RS, Brazil, September/2003.

[4] M. A. Carvalho; "Application of Saturated Reactors in Systems of Transmission” (in Portuguese), XIII SNPTEE, Camboriú-SC, Brazil, October/1995.

[5] E. Friedlander, K. M. Jones; "Saturated reactors for Long Distance Bulk Power Lines"; Electrical Review, 27th June/1969, pp 940 - 943.

[6] I.M. Faria, "Análise no desempenho do sistema de transmissão de energia após a utilização de reatores lineares e reatores a núcleo saturado para a regulação da tensão"(in Portuguese),Final Paper,UFMT, Cuiabá-Mt, Brazil, 3rd October 2016 